BMJ Open

Diabetes

Research

\& Care

\section{Association between a biomarker of glucose spikes, 1,5-anhydroglucitol, and cancer mortality}

To cite: Kira S, Ito C, Fujikawa R, et al. Association between a biomarker of glucose spikes, 1,5-anhydroglucitol, and cancer mortality. BMJ Open Diab Res Care 2020;8:e001607. doi:10.1136/ bmjdrc-2020-001607

Received 26 May 2020 Revised 25 June 2020 Accepted 2 July 2020
Check for updates

\section{(c) Author(s) (or their} employer(s)) 2020. Re-use permitted under CC BY-NC. No commercial re-use. See rights and permissions. Published by BMJ.

${ }^{1}$ Grand Tower Medical Court Life Care Clinic, Hiroshima, Japan

${ }^{2}$ Hiroshima Atomic Bomb Casualty Council, Hiroshima, Japan

${ }^{3}$ Faculty of Pharmaceutical Science, Hiroshima University, Hiroshima, Japan

Correspondence to Dr Sakurako Kira; skira.medical-court@uvgtmedical.com

\section{ABSTRACT}

Introduction 1,5-Anhydroglucitol (1,5-AG) is a biomarker of glucose spikes. To evaluate the effect of acute glucose excursions on cancer death, we clarified the association between 1,5-AG and cancer mortality among Japanese individuals with normal glucose tolerance.

Research design and methods We measured 1,5-AG in 6783 (2842 men, 3941 women) individuals with normal fasting and 2-hour plasma glucose who received a $75 \mathrm{~g}$ oral glucose tolerance test between 1994 and 2012. They were followed for mortality until August 2013. A systematic review of death certificates was used to confirm the cause of death. We divided the participants into four groups according to the quartile of 1,5-AG level at registration. We used Cox regression to clarify the association between 1,5-AG levels and cancer mortality with multivariate adjustment for possible confounders.

Results During the follow-up period (median, 10.0 years), 140 men and 109 women died of cancer. The HR for cancer mortality of the lowest quartile group was higher than that of the highest quartile group in men (HR, 2.62; $95 \% \mathrm{Cl}, 1.60$ to 4.41$)$ and in women ( $\mathrm{HR}, 1.47 ; 95 \% \mathrm{Cl}$, 0.88 to 2.47 ). These associations were not attenuated with further adjustment for $\mathrm{HbA} 1 \mathrm{C}$.

Conclusions 1,5-AG was associated with high risk of cancer mortality in Japanese men after adjustment for HbA1c.

\section{INTRODUCTION}

Individuals with type 2 diabetes have high risk of cancer and cancer mortality. The association between diabetes and cancer risk is not fully understood; however, hyperglycemia as well as hyperinsulinemia and chronic inflammation may be involved. Hyperglycemia promotes oxidative stress in the presence of mitochondrial glucose oxidation, ${ }^{1}$ and high oxidative stress causes DNA damage. ${ }^{2}$ Furthermore, there may be a cascade of events that proceeds hyperglycemia from increased oxidative stress to DNA modifications/mutations resulting in a high incidence of cancer. $^{134}$

Compared with sustained hyperglycemia, acute glucose excursions cause more oxidative stress. ${ }^{56}$ In addition, in normal subjects,

\section{Significance of this study}

What is already known about this subject?

- Compared with sustained hyperglycemia, acute glucose excursions (glucose spike) cause more oxidative stress.

- 1,5-Anhydroglucitol (1,5-AG) is a marker of glucose spikes.

What are the new findings?

1,5-AG level was associated with increased cancer mortality in Japanese men with normal glucose tolerance after adjustment for glycated hemoglobin.

How might these results change the focus of research or clinical practice?

1,5-AG may be a useful indicator for cancer mortality.

- To reduce cancer mortality, it may be important to modify lifestyle for the prevention of glucose spike after meal.

glucose oscillations results in increased endothelial dysfunction and oxidative stress. ${ }^{7}$

1,5-Anhydroglucitol (1,5-AG) is inversely associated with hyperglycemia and is thought to be a useful indicator of glucose peaks over a short term. ${ }^{89}$ Levels of 1,5-AG are more indicative of short-term glycemic status compared with levels of glycated hemoglobin (HbAlc). Moreover, 1,5-AG level reflects postprandial hyperglycemia and glycemic variability, which are not possible by HbAlc measurements. ${ }^{9} 10$ Therefore, we hypothesized that low levels of 1,5-AG, a marker of acute glucose excursion (glucose spike), is able to predict longterm cancer mortality among individuals with normal glucose tolerance (NGT).

\section{RESEARCH DESIGN AND METHODS}

\section{Data sources}

We examined Japanese individuals living in Hiroshima City, having a fixed population of atomic bomb survivors, who were born before May 1946 and received health examinations according to Japanese medical laws. ${ }^{11}$ 


\section{Study subjects}

A total of 12840 men and women who had not been diagnosed with diabetes underwent a health examination as well as a $75 \mathrm{~g}$ oral glucose tolerance test ( $75 \mathrm{~g}$ OGTT) between 1994 and 2012. We excluded 114 men and women who were within $1 \mathrm{~km}$ from the hypocenter to avoid the effects of radiation on cancer mortality. ${ }^{12}$ The following participants were also excluded from the study: 48 with severe inflammatory disease or malignancy at baseline, 17 who died within 1 year after registering in the study, 467 without measurement of 1,5-AG levels, 1607 who were diagnosed with diabetes by $75 \mathrm{~g}$ OGTT, and 3804 who were diagnosed with impaired fasting glucose (IFG) or impaired glucose tolerance (IGT). Therefore, we assessed 6783 individuals (2842 men with a mean age of 66.7 years, SD, 6.6 years; and 3941 women with a mean age of 68.1 years, $\mathrm{SD}, 7.0$ years).

\section{Definition of outcomes}

Mortality among the participants was prospectively assessed until August 2013. Cause of death was determined based on death certificates and medical records. Individual diagnoses were classified using the International Classification of Death (ICD, Ninth edition). Solid cancer deaths were defined as code 140-199. We distinguished hematology neoplasm (ICD, 200-208) from the definition of cancer death to eliminate the influence of radiation effects. ${ }^{12}$

\section{Baseline examination}

All participants underwent a $75 \mathrm{~g}$ OGTT at 08:30 after an overnight fast ( $\geq 12$ hours), and their plasma glucose (PG) levels were measured by the glucose oxidase method. Glucose tolerance status was defined according to the 2010 diagnostic criteria of the Japan Diabetes Society. ${ }^{13}$ The participants were divided into diabetic, borderline (IFG and/or IGT), and NGT groups.

The participants' fasting immunoreactive insulin (FIRI) levels were measured by the enzyme immunoassay method. The homeostasis model assessment of insulin resistance (HOMA-R) status was calculated $($ FIRI $(\mu \mathrm{U} / \mathrm{mL}) \times$ FPG (fasting plasma glucose) $(\mathrm{mg} /$ dL) / 405).

The participants' 1,5-AG levels were measured by the enzyme method. The participants' HbAlc levels were measured by high-performance liquid chromatography or immunoassay, which were calibrated using wholeblood standard from the Japanese Diabetes Society. The data were converted using the National Glycohemoglobin Standardization Program converter. ${ }^{13}$

Fasting serum samples were used to perform liver and renal function as well as lipid tests. Anthropometric measurements (height and body weight) were assessed with participants wearing thin clothes.

Nurses interviewed the participants and collected data regarding their medical history, family history, medication, and smoking habits. In addition, alcohol intake was evaluated by a dietitian, and the participants were classified as non-drinkers, mild drinkers (ethanol intake of $0.1-30 \mathrm{~g} /$ day), and drinkers (ethanol intake of $>30 \mathrm{~g}$ / day).

The participants were also divided into three groups based on radiation exposure status: those who were within $2 \mathrm{~km}$ from the hypocenter, those over $2 \mathrm{~km}$ from the hypocenter, and those with early entrance.

\section{Ethical considerations}

This study was approved by the Central Institutional Review Board of the Hiroshima Atomic Bomb Casualty Council Health Management and Promotion Center. Informed consent was obtained from the participants, and their data were anonymized to the researchers.

\section{Statistical analyses}

We evaluated the association between cancer mortality and 1,5-AG by comparing the mortality risk of the 1,5-AG groups with the lowest quartile group of 1,5-AG levels by Cox proportional hazards model with multivariate adjustment for possible confounders, such as age, body mass index, smoking, alcohol intake, and radiation effects (model 1 ). HOMA-R was added to the factors in model 1 (model 2). HbA1c was also added to the factors in model 2 (model 3 ). In addition, the association between 1,5-AG and cancer mortality was evaluated using 1,5-AG level as a continuous variable with multivariate adjustment for age, body mass index, smoking, alcohol intake, radiation effects, HOMA-R, and HbAlc. All analyses were performed according to sex. Proportional hazards assumptions were assessed using log-log curves and Shoenfeld residuals.

All analyses were performed using JMP software (SAS Institute, Cary, North Carolina, USA) and R-3.5.1 (The R Foundation for Statistical Computing, Vienna, Austria). All tests were two-sided and $95 \%$ CIs were calculated as Wald CIss.

\section{RESULTS}

\section{Distribution of 1,5 -AG levels by sex}

The 1,5-AG levels in 2842 men showed normal distribution. The median value was $22.8 \mu \mathrm{g} / \mathrm{mL}$ (minimum, $3.2 \mu \mathrm{g} / \mathrm{mL}$; maximum, $64.7 \mu \mathrm{g} / \mathrm{mL}$ ), and the mean value was $23.2 \mu \mathrm{g} / \mathrm{mL}$ (SD, 7.9). The participants were divided into four groups according to the quartiles of their 1,5-AG level (first quartile, $28.2-64.7 \mu \mathrm{g} / \mathrm{mL}$; second quartile, 22.8-28.1 $\mu \mathrm{g} / \mathrm{mL}$; third quartile, $17.8-22.7 \mu \mathrm{g} / \mathrm{mL}$; and fourth quartile, $3.2-17.7 \mu \mathrm{g} / \mathrm{mL}$ ).

The 1,5-AG levels in 3941 women showed normal distribution. The median value was $18.9 \mu \mathrm{g} / \mathrm{mL}$ (minimum, $1.0 \mu \mathrm{g} / \mathrm{mL}$; maximum, $48.5 \mu \mathrm{g} / \mathrm{mL}$ ), and the mean value was $19.4 \mu \mathrm{g} / \mathrm{mL}$ (SD, 6.8). The participants were divided into four groups according to the quartiles of their 1,5-AG level (first quartile, 23.5-48.5 $\mathrm{g} / \mathrm{mL}$; second quartile, $18.9-23.4 \mu \mathrm{g} / \mathrm{mL}$; third quartile, $14.7-18.8 \mu \mathrm{g} / \mathrm{mL}$; and fourth quartile, $1.0-14.6 \mu \mathrm{g} / \mathrm{mL}$ ). 
Table 1 Baseline characteristics of men based on the 1,5-AG level quartile

\begin{tabular}{|c|c|c|c|c|}
\hline & First quartile & Second quartile & Third quartile & Fourth quartile \\
\hline $\mathrm{N}$ & 718 & 709 & 713 & 702 \\
\hline 1,5-AG ( $\mu \mathrm{g} / \mathrm{mL})$ & $33.4(4.9)$ & $25.4(1.6)$ & $20.3(1.4)$ & $13.4(3.2)$ \\
\hline 1,5-AG ( $\mu \mathrm{g} / \mathrm{mL})$ (minimum, maximum) & $28.2,64.7$ & $22.8,28.1$ & $17.8,22.7$ & $3.2,17.7$ \\
\hline Age (years) & $66.9(6.5)$ & $66.5(6.4)$ & $66.5(6.6)$ & $67.8(6.7)$ \\
\hline BMI $\left(\mathrm{kg} / \mathrm{m}^{2}\right)$ & $22.7(2.7)$ & $22.9(2.7)$ & $23.2(2.8)$ & $22.7(2.8)$ \\
\hline $\mathrm{FPG}(\mathrm{mg} / \mathrm{dL})$ & $95.7(6.2)$ & $95.6(6.4)$ & $95.9(6.6)$ & $95.6(6.5)$ \\
\hline 30 min PG (mg/dL) & $151.6(24.7)$ & $151.5(24.0)$ & $155.3(26.2)$ & 162.1 (31.9) \\
\hline 1-hour PG (mg/dL) & $145.8(34.9)$ & $146.2(35.7)$ & $150.4(37.3)$ & $157.3(43.5)$ \\
\hline 2-hour PG (mg/dL) & $107.7(20.3)$ & $107.0(19.4)$ & $109.2(20.3)$ & $106.1(22.5)$ \\
\hline 3-hour PG (mg/dL) & $83.5(21.8)$ & $82.7(21.1)$ & $83.5(21.5)$ & $84.0(22.6)$ \\
\hline$\Delta 30 \min P G(m g / d L)$ & $55.9(23.2)$ & $55.9(22.2)$ & $59.4(24.4)$ & $66.5(30.3)$ \\
\hline$\Delta 1$-hour PG (mg/dL) & $50.1(33.6)$ & $50.6(34.3)$ & $54.5(36.1)$ & $61.7(42.1)$ \\
\hline FIRI $(\mu U / m L)$ & $5.1(0.2)$ & $5.2(0.1)$ & $5.5(0.1)$ & $5.1(0.1)$ \\
\hline HOMA-R & $1.21(0.70)$ & $1.23(0.75)$ & $1.32(0.74)$ & $1.22(0.74)$ \\
\hline $\mathrm{HbA1c}(\%)$ & $5.5(0.3)$ & $5.5(0.3)$ & $5.5(0.3)$ & $5.6(0.4)$ \\
\hline Current smoker & $240(33.4)$ & $193(27.2)$ & $197(27.6)$ & $186(26.5)$ \\
\hline \multicolumn{5}{|l|}{ Alcohol consumption } \\
\hline Non-drinker & $257(35.8)$ & $249(35.1)$ & $256(35.9)$ & $248(35.3)$ \\
\hline $0.1-30.0 \mathrm{~g} / \mathrm{day}$ & $282(59.3)$ & 257 (36.3) & 247 (34.6) & $262(37.3)$ \\
\hline Over $30.1 \mathrm{~g} /$ day & $179(24.9)$ & $203(28.6)$ & $210(29.5)$ & $192(27.4)$ \\
\hline \multicolumn{5}{|l|}{ Radiation exposure status } \\
\hline Within $2.0 \mathrm{~km}$ & $111(15.5)$ & $112(15.8)$ & $100(14.0)$ & $114(16.2)$ \\
\hline Over $2.0 \mathrm{~km}$ & $283(39.4)$ & $290(40.9)$ & $300(42.1)$ & $296(42.2)$ \\
\hline Early entrance & $324(45.1)$ & $307(43.3)$ & $313(43.7)$ & $292(41.6)$ \\
\hline
\end{tabular}

Data are shown as the mean (SD) or $\mathrm{n}(\%)$.

1,5-AG, 1,5-anhydroglucitol; BMI, body mass index; FIRI, fasting immunoreactive insulin; FPG, fasting plasma glucose; HbA1c, glycated hemoglobin; HOMA-R, homeostasis model assessment of insulin resistance; PG, plasma glucose.

\section{Baseline characteristics according to the quartiles of 1,5-AG} levels

The baseline characteristics of each group (first, second, third, and fourth quartiles of 1,5-AG levels) for men and women are shown in tables 1 and 2, respectively. Although there were no differences in levels of FPG, 2-hour PG, and HbAlc, 30 min PG and 1-hour PG levels increased with the quartile of 1,5-AG levels.

Increase in PG $30 \mathrm{~min}$ and 1 hour after loading from fasting level was calculated ( $\Delta 30 \mathrm{~min} P G, \Delta 1$-hour PG), and both $\Delta 30$ min PG and $\Delta 1$-hour PG increased with the quartile of 1,5-AG levels for both men and women.

\section{Outcome}

The median follow-up period was 10.0 (IQR: 6.1-14.0) years, and 431 men and 358 women died during follow-up. According to their death certificates, 140 men and 118 women died of solid cancer (ICD, 140-199), 14 men and 7 women died of leukemia (ICD, 200-208), 67 men and 35 women died of infection (ICD, 1-139, 460-466, 481-487), 40 men and 60 women died of cerebrovascular disease (ICD, 450-438), 25 men and 17 women died of ischemic heart disease (ICD, 410-414), 5 men and 6 women died of liver disease (ICD, 570-573), and 11 men and 6 women died of kidney disease (ICD, 580-589).

Among the 140 men who died of solid cancer, 44 died of lung cancer, 19 of stomach cancer, 15 of pancreatic cancer, 14 of liver cancer, 10 of colon cancer, 9 of esophageal cancer, 5 of gall bladder cancer, 4 of prostate cancer, 2 of kidney cancer, 2 of bladder cancer, and 16 of other cancers. Among the 109 women who died from cancer, 20 died of lung cancer, 19 of stomach cancer, 17 of pancreatic cancer, 11 of liver cancer, 7 of colon cancer, 6 of breast cancer, 6 of esophageal cancer, 5 of gall bladder cancer, 3 of uterine cancer, 3 of bladder cancer, and 12 of other cancers.

\section{Crude cancer mortality rate by quartiles of 1,5-AG levels}

The event rates for all solid cancer deaths for each quartile group of 1,5-AG levels were 3.11, 5.42, 4.36, and 8.00 per 1000 person-years, respectively, in men, and 2.53, 2.35, 2.65, and 3.67 per 1000 person-years, respectively, in women (table 3 ). 
Table 2 Baseline characteristics of women based on the 1,5-AG level quartile

\begin{tabular}{|c|c|c|c|c|}
\hline & First quartile & Second quartile & Third quartile & Fourth quartile \\
\hline $\mathrm{N}$ & 996 & 996 & 983 & 966 \\
\hline $1,5-A G(\mu g / m L)$ & $28.4(4.3)$ & $21.0(81.3)$ & $16.8(1.2)$ & $11.3(2.6)$ \\
\hline $1,5-\mathrm{AG}(\mu \mathrm{g} / \mathrm{mL})$ (minimum, maximum) & $23.5,48.5$ & $18.9,23.4$ & $14.7,18.8$ & $1.0,14.6$ \\
\hline Age (years) & $67.9(6.8)$ & $67.6(6.9)$ & $67.7(7.0)$ & $68.6(7.0)$ \\
\hline $\mathrm{BMI}\left(\mathrm{kg} / \mathrm{m}^{2}\right)$ & $22.5(3.3)$ & $22.6(3.1)$ & $22.6(3.2)$ & $22.3(3.2)$ \\
\hline FPG (mg/dL) & $93.6(7.1)$ & $93.8(6.8)$ & $93.9(6.9)$ & $94.2(6.9)$ \\
\hline 30 min PG (mg/dL) & $146.1(26.7)$ & $146.7(26.5)$ & $147.2(27.1)$ & $150.6(31.5)$ \\
\hline 1-hour PG (mg/dL) & $133.5(35.4)$ & $134.9(34.9)$ & $137.1(36.7)$ & 139.9 (39.9) \\
\hline 2-hour PG (mg/dL) & $108.8(18.5)$ & $108.6(18.8)$ & $108.4(18.8)$ & $108.8(19.9)$ \\
\hline 3-hour PG (mg/dL) & $91.8(21.9)$ & $93.5(22.1)$ & $94.2(22.1)$ & $94.7(21.9)$ \\
\hline$\Delta 30$ min $P G(m g / d L)$ & $52.4(24.2)$ & $52.9(24.4)$ & $53.3(24.8)$ & $56.5(29.4)$ \\
\hline$\Delta 1$-hour PG (mg/dL) & $39.9(33.2)$ & $41.1(33.2)$ & $43.2(34.7)$ & $45.7(37.7)$ \\
\hline $\mathrm{FIRI}(\mu \mathrm{U} / \mathrm{mL})$ & $5.5(0.1)$ & $5.5(0.1)$ & $5.5(0.1)$ & $5.3(0.1)$ \\
\hline HOMA-R & $1.28(0.70)$ & $1.29(0.74)$ & $1.29(0.76)$ & $1.25(0.77)$ \\
\hline HbA1c (\%) & $5.6(0.3)$ & $5.6(0.3)$ & $5.6(0.3)$ & $5.6(0.3)$ \\
\hline Current smoker & $37(3.7)$ & $31(3.1)$ & $29(3.0)$ & $31(3.2)$ \\
\hline \multicolumn{5}{|l|}{ Alcohol consumption } \\
\hline Non-drinker & $830(83.3)$ & $813(81.6)$ & $798(81.2)$ & $771(79.8)$ \\
\hline $0.1-30.0 \mathrm{~g} / \mathrm{day}$ & $148(14.9)$ & $164(16.5)$ & $170(17.3)$ & $183(18.9)$ \\
\hline Over $30.1 \mathrm{~g} /$ day & $18(1.8)$ & $19(1.9)$ & $15(1.5)$ & $12(1.2)$ \\
\hline \multicolumn{5}{|l|}{ Radiation exposure status } \\
\hline Within $2.0 \mathrm{~km}$ & $151(15.2)$ & $172(17.3)$ & $166(16.9)$ & $168(17.4)$ \\
\hline Over $2.0 \mathrm{~km}$ & $404(40.6)$ & $390(39.2)$ & $403(41.0)$ & $396(41.0)$ \\
\hline Early entrance & $491(44.3)$ & $434(43.6)$ & $414(42.1)$ & $402(41.6)$ \\
\hline
\end{tabular}

Data are shown as the mean (SD) or $\mathrm{n}(\%)$.

1,5-AG, 1,5-anhydroglucitol; BMI, body mass index; FIRI, fasting immunoreactive insulin; FPG, fasting plasma glucose; HbA1c, glycated hemoglobin; HOMA-R, homeostasis model assessment of insulin resistance; PG, plasma glucose.

Table 3 Cancer mortality and adjusted HRs $(95 \% \mathrm{Cl})$ for cancer death by $1,5-\mathrm{AG}$ level quartile

\begin{tabular}{|c|c|c|c|c|c|}
\hline & Events/n & $\begin{array}{l}\text { Event rate (per } \\
1000 \text { person-years) }\end{array}$ & $\begin{array}{l}\text { Model } 1 \\
\text { HR }(95 \% \mathrm{CI})\end{array}$ & $\begin{array}{l}\text { Model } 2 \\
\text { HR }(95 \% \mathrm{Cl})\end{array}$ & $\begin{array}{l}\text { Model } 3 \\
\text { HR }(95 \% \mathrm{Cl})\end{array}$ \\
\hline \multicolumn{6}{|l|}{ Men } \\
\hline First quartile & $22 / 718$ & 3.11 & 1 (reference) & 1 (reference) & 1 (reference) \\
\hline Second quartile & $36 / 709$ & 5.42 & 1.95 (1.15 to 3.37$)$ & 1.95 (1.15 to 3.37 ) & 1.96 (1.16 to 3.38$)$ \\
\hline Third quartile & $30 / 713$ & 4.36 & 1.55 (0.89 to 2.72$)$ & $1.54(0.89$ to 2.71$)$ & 1.54 (0.89 to 2.70$)$ \\
\hline Fourth quartile & $52 / 702$ & 8.00 & $2.62(1.60$ to 4.41$)$ & $2.62(1.61$ to 4.41$)$ & 2.55 (1.56 to 4.31$)$ \\
\hline \multicolumn{6}{|l|}{ Women } \\
\hline First quartile & $26 / 996$ & 2.53 & 1 (reference) & 1 (reference) & 1 (reference) \\
\hline Second quartile & $23 / 996$ & 2.35 & 1.08 (0.58 to 1.81$)$ & 1.04 (0.59 to 1.82$)$ & 1.04 (0.59 to 1.82$)$ \\
\hline Third quartile & $26 / 983$ & 2.65 & $1.11(0.64$ to 1.92$)$ & $1.12(0.65$ to 1.94$)$ & 1.12 (0.64 to 1.93$)$ \\
\hline Fourth quartile & $34 / 996$ & 3.67 & 1.47 (0.88 to 2.47$)$ & 1.47 (0.88 to 2.48$)$ & 1.45 (0.87 to 2.44$)$ \\
\hline
\end{tabular}

Model 1: HR adjusted for age, body mass index, smoking status, alcohol intake, and radiation effects using multiple Cox proportional hazard model.

Model 2: HR adjusted for factors used in model 1 as well as HOMA-R.

Model 3: HR adjusted for factors used in model 2 as well as HbA1c.

1,5-AG, 1,5-anhydroglucitol; HbA1c, glycated hemoglobin; HOMA-R, homeostasis model assessment of insulin resistance. 
Table 4 Adjusted HR for cancer mortality of 1,5-AG value (per $10 \mu \mathrm{g} / \mathrm{mL})$

\begin{tabular}{llll}
\hline & Model 1 & Model 2 & Model 3 \\
\hline Men & $1.37(95 \% \mathrm{Cl} \mathrm{1.11}$ to 1.69$)$ & $1.37(95 \% \mathrm{Cl} 1.11$ to 1.69$)$ & $1.35(95 \% \mathrm{Cl} 1.09$ to 1.66$)$ \\
Women & $1.16(95 \% \mathrm{Cl} 0.89$ to 1.52$)$ & $1.16(95 \% \mathrm{Cl} 0.89$ to 1.52$)$ & $1.15(95 \% \mathrm{Cl} \mathrm{0.88} \mathrm{to} 1.51)$ \\
\hline
\end{tabular}

Model 1: HR adjusted for age, body mass index, smoking status, alcohol intake, and radiation effects using multiple Cox proportional hazard model.

Model 2: HR adjusted for factors used in model 1 as well as HOMA-R.

Model 3: HR adjusted for factors used in model 2 as well as HbA1c.

1,5-AG, 1,5-anhydroglucitol; HbA1c, glycated hemoglobin; HOMA-R, homeostasis model assessment of insulin resistance.

\section{Cancer mortality risk by 1,5 -AG levels}

The HRs for cancer mortality in participants in the second, third, and fourth quartiles of 1,5-AG levels, which was adjusted for age, body mass index, smoking status, alcohol intake, and radiation effects, compared with that of the first quartile are shown in table 3. The HR of the fourth quartile group was significantly high in men (model 1: HR, 2.62; 95\% CI, 1.60 to 4.41). In model 2 and model 3, the multivariate-adjusted HRs in participants in the fourth quartile group of 1,5-AG levels compared with that of the first quartile were also significantly higher (HR, 2.62; 95\% CI, 1.61 to 4.41 in model 2, HR, 2.55; $95 \%$ CI, 1.56 to 4.31 in model 3) (table 3 ). In women, the HR increased with the degree of 1,5-AG quartile group; however, it was not significant.

The shape of the association of 1,5-AG, as a continuous variable, with cancer mortality was well-described as a linear relationship (even when we fit a spline, the shape was very close to the linear). The HRs for cancer death with low 1,5-AG levels (per $10 \mu \mathrm{g} / \mathrm{mL}$ ) in men and women were 1.37 (95\% CI, 1.11 to 1.69 ) and $1.16(95 \%$ CI, 0.89 to 1.52), respectively, in model 1; the HRs in men and women were 1.37 (95\% CI, 1.11 to 1.69$)$ and 1.16 (95\% CI, 0.89 to 1.52 ), respectively, in model 2; and the HRs in men and women were 1.35 (95\% CI, 1.09 to 1.66$)$ and 1.15 (95\% CI, 0.88 to 1.51 ), respectively, in model 3 (table 4).

\section{DISCUSSION}

This study showed that the 1,5-AG level was associated with increased risk of cancer death in Japanese men with NGT status. Furthermore, we found that 1,5-AG level was also associated with cancer mortality after adjustment for HbAlc. To our knowledge, this is the first study to show a relationship between 1,5-AG and cancer mortality.

A high incidence of cancer in patients with diabetes involves hyperglycemia. Chronic hyperglycemia, as evaluated by measuring HbAlc levels, correlates with increased risk of cancer. ${ }^{14}$ However, there is a study that shows that postprandial hyperglycemia may be associated with cancer mortality in patients with type 2 diabetes independent of HbAlc levels. ${ }^{15}$ Furthermore, they show that fasting glucose levels are non-linearly associated with risk of death. Fasting glucose levels exceeding $100 \mathrm{mg} /$ dL $(5.6 \mathrm{mmol} / \mathrm{L})$ but not levels of 70 to $100 \mathrm{mg} / \mathrm{dL}(3.9$ to $5.6 \mathrm{mmol} / \mathrm{L}$ ) were associated with high risk; however, association with cancer death tended to plateau at higher levels. ${ }^{16}$ Therefore, acute glucose excursions may result in higher rates of cancer death than continuous hyperglycemia.

There are several reports regarding the effects of glucose oscillation on diabetic complications and arteriosclerosis in humans. One report suggested that, compared with constant hyperglycemia, oscillating glucose levels have more deleterious effects on endothelial function and increases oxidative stress, which cause cardiovascular complications in diabetes. ${ }^{7}$ Moreover, glucose spikes were found to be important factors for endothelial function and oxidative stress. ${ }^{17}$ Schisano et al found that glucose oscillations resulted in increased p53 activation compared with continuous hyperglycemia. ${ }^{18}$ In patient with p53 activation, DNA damage may have occurred, which may increase the probability of cancer in the future.

It is difficult to detect glucose spikes in daily practice; however, in recent years, studies using a continuous glucose monitoring system found that $1,5-\mathrm{AG}$ is a useful indicator of blood glucose excursions. ${ }^{10} 19$

To clarify the significance of glucose spikes, we measured 1,5-AG in subjects with normal fasting and 2-hour PG range. We found that $\Delta 30 \mathrm{~min} P G$ and $\Delta 1$-hour PG increased with the quartile of 1,5-AG levels in both men and women. Therefore, in this study, the level of 1,5-AG is considered to be an indicator of glucose spikes. We found that glucose spikes were present even in subjects with NGT, and that those with glucose spikes were more likely to die of cancer in the future. However, postload blood glucose obtained using an OGTT is not equivalent to postprandial blood glucose.

Not only glucose spikes but also hyperinsulinemia is associated with cancer mortality. Glucose spike postmeal also induce insulin hyper secretion. Thus, relationship between 1,5-AG and cancer mortality might be considered including insulin action.

The 1,5-AG excretion rate depends on the renal threshold of glucose.$^{20}$ There are reports showing differences between males and females in the levels of 1,5-AG. In the Chinese population, 1,5-AG levels in men were significantly higher than in women. ${ }^{21}$ Therefore, in this study, we clarified the results according to sex.

In women, no significant relationship between serum 1,5-AG levels and risk of cancer death was observed; 
however, the risk ratio increased gradually. This study may have been insufficient to detect an association. Similarly, the Suita study, which clarified the association between cardiovascular disease and 1,5-AG in a Japanese cohort, showed a significant association in men but not in women. ${ }^{22}$ Although the reason for the differing results between men and women is unclear, there may be sexbased differences in the clinical significance of 1,5-AG in the Japanese population. Further studies are required to clarify this discrepancy.

This study had several strengths. In addition to a large cohort, all tests, including those measuring 1,5-AG levels, were performed using the same methods, and the participants were interviewed using the same protocol, which allowed us to address confounding factors such as smoking and alcohol intake. Moreover, the complete prognosis of most participants was available.

The study also had several limitations. First, we relied on a single measurement of 1,5-AG; however, 1,5-AG levels have shown to truck well within individuals over time. ${ }^{23}$ Second, some participants may have had latent cancer at registration despite most having previously undergone numerous annual cancer screening examinations such as chest radiography, upper gastrointestinal examinations, stool tests, mammography, and cervical cytology. To mitigate this issue, we excluded participants who died within 1 year after registration. Third, in the multivariable analysis, other potential risk factors for cancer (eg, occupation, food intake, and physical activities) were not included. Fourth, most participants were survivors of the atomic bomb, and radiation may have influenced the occurrence of cancer. According to reports by the Japan Ministry of Health, Labor and Welfare ${ }^{24}$ cancer is the most common cause of Japanese deaths. The next common cause is infection, and the third is cerebrovascular disorders. In our study, similar results were found. Nationally, the first, second, and third most common causes of organ-specific cancer deaths in Japanese men are lung, gastric, and colon cancer, respectively. In Japanese women, the first, second, and third most common causes are colon, lung, and pancreatic cancer, respectively. In our study, the first, second, and third most common causes of organ-specific cancer in men were lung, liver, and gastric cancer, respectively, and in women, lung, gastric, and pancreatic cancer, respectively. Compared with the national results, the mortality rate of colon cancer in our subjects was low. This may be due to differences in age distribution between our subjects and those nationwide. Overall, our subjects had similar characteristics to the general Japanese population despite having being exposed to radiation. Furthermore, we added radiation exposure status to the analysis as an adjustment factor. Fifth, the outcome of this study was cancer mortality. To clarify the pathophysiological relationship between 1,5-AG and the onset and/or development of cancer, further studies are required.

In conclusion, we found that $1,5-\mathrm{AG}$ was associated with cancer mortality in Japanese men with NGT after adjustment for HbA1c. Our studies suggest a potential harmful effect of glucose spikes on cancer mortality. To reduce cancer mortality, glucose spikes postmeal should be avoided. It may be important to modify lifestyle for the prevention of glucose spikes. Further studies are required to clarify whether $1,5-\mathrm{AG}$ may be a useful indicator for cancer mortality.

Acknowledgements The authors thank the study staff and participants for their contributions. The authors also thank Professor Hideshi Kawakami (Department of Epidemiology, Research Institute for Radiation and Medicine, Hiroshima University, Hiroshima, Japan) and Dr Genshi Egusa (Egusa Genshi Clinic, Hiroshima, Japan) for their assistance with this study.

Contributors SK contributed to the study design, researched the data, interpreted the results, and wrote the article. $\mathrm{Cl}$ established the database of medical examinations including OGTT. RF reviewed the manuscript and contributed to the discussion. MM provided advice on the statistical analyses and contributed to the writing and editing of this manuscript. SK is the guarantor of this work and had full access to all the data in this study and takes responsibility for the integrity of the data and accuracy of the data analysis.

Funding The authors have not declared a specific grant for this research from any funding agency in the public, commercial or not-for-profit sectors.

Competing interests None declared.

\section{Patient consent for publication Not required.}

Ethics approval This study was approved by the Central Institutional Review Board of the Hiroshima Atomic Bomb Casualty Council Health Management and Promotion Center Japan (No 34) and by the Institutional Review Board of Grand Tower Medical Court in Hiroshima Japan (№ 2019-01).

Provenance and peer review Not commissioned; externally peer reviewed.

Data availability statement Data sharing not applicable as no datasets generated and/or analyzed for this study.

Open access This is an open access article distributed in accordance with the Creative Commons Attribution Non Commercial (CC BY-NC 4.0) license, which permits others to distribute, remix, adapt, build upon this work non-commercially, and license their derivative works on different terms, provided the original work is properly cited, appropriate credit is given, any changes made indicated, and the use is non-commercial. See: http://creativecommons.org/licenses/by-nc/4.0/

ORCID iDs

Sakurako Kira http://orcid.org/0000-0001-5999-8459

Munechika Misumi http://orcid.org/0000-0003-2698-4880

\section{REFERENCES}

1 Chang YC, Chung LM. The role of oxidative stress in the pathogenesis of type 2 diabetes: from molecular mechanism to clinical implication. Am J Trans/ Res 2010;2:316-31.

2 Akatsuka S, Toyokuni S. Genome-wide assessment of oxidatively generated DNA damage. Free Radic Res 2012;46:523-30.

3 Giacco F, Brownlee M. Oxidative stress and diabetic complications. Circ Res 2010;107:1058-70.

4 Cairns RA, Harris IS, Mak TW. Regulation of cancer cell metabolism. Nat Rev Cancer 2011;11:85-95.

5 Monnier L, Mas E, Ginet C, et al. Activation of oxidative stress by acute glucose fluctuations compared with sustained chronic hyperglycemia in patients with type 2 diabetes. JAMA 2006;295:1681-7.

6 La Sala L, Cattaneo M, De Nigris V, et al. Oscillating glucose induces microRNA-185 and impairs an efficient antioxidant response in human endothelial cells. Cardiovasc Diabetol 2016;15:71.

7 Ceriello A, Esposito K, Piconi L, et al. Oscillating glucose is more deleterious to endothelial function and oxidative stress than mean glucose in normal and type 2 diabetic patients. Diabetes 2008;57:1349-54.

8 Dungan KM. 1,5-anhydroglucitol (GlycoMark ${ }^{\mathrm{TM}}$ ) as a marker of shortterm glycemic control and glycemic excursions. Expert Rev Mol Diagn 2008;8:9-19.

9 Yamanouchi T, Ogata N, Tagaya T, et al. Clinical usefulness of serum 1,5-anhydroglucitol in monitoring glycaemic control. The Lancet 1996;347:1514-8. 
10 Dungan KM, Buse JB, Largay J, et al. 1,5-anhydroglucitol and postprandial hyperglycemia as measured by continuous glucose monitoring system in moderately controlled patients with diabetes. Diabetes Care 2006;29:1214-9.

11 Shigematu I, Ito $\mathrm{C}$, Kamada $\mathrm{K}$, et al. Effects of $\mathrm{A}-\mathrm{Bomb}$ radiation on the human body. Bunkodo, 1995.

12 Preston DL, Pierce DA, Shimizu Y, et al. Effect of recent changes in atomic bomb survivor dosimetry on cancer mortality risk estimates. Radiat Res 2004;162:377-89.

13 Seino Y, Nanjo K, Tajima N, et al. Report of the Committee on the classification and diagnostic criteria of diabetes mellitus. Diabetol Int 2010;1:2-20.

14 de Beer JC, Liebenberg L. Does cancer risk increase with HbA1c, independent of diabetes? Br J Cancer 2014;110:2361-8.

15 Takao T, Takahashi K, Suka M, et al. Association between postprandial hyperglycemia at clinic visits and all-cause and cancer mortality in patients with type 2 diabetes: a long-term historical cohort study in Japan. Diab Res Clin Pract 2019;148:152-9.

16 The Emerging Risk Factors Collaboration. Diabetes mellitus, fasting glucose, and risk of cause-specific death. $N$ Engl J Med 2011;364:829-41.

17 Ceriello A, Esposito K, Piconi L, et al. Glucose "peak" and glucose "spike": Impact on endothelial function and oxidative stress. Diab Res Clin Pract 2008;82:262-7.
18 Schisano B, Tripathi G, McGee K, et al. Glucose oscillations, more than constant high glucose, induce p53 activation and a metabolic memory in human endothelial cells. Diabetologia 2011;54:1219-26.

19 Suwa T, Ohta A, Matsui T, et al. Relationship between clinical markers of glycemia and glucose excursion evaluated by continuous glucose monitoring (CGM). Endocr J 2010;57:135-40.

20 Kilpatrick ES, Keevil BG, Richmond KL, et al. Plasma 1,5 -anhydroglucitol concentrations are influenced by variations in the renal threshold for glucose. Diabet Med 1999;16:496-9.

21 Zhou Q, Shi D-B, Lv L-Y. The establishment of biological reference intervals of nontraditional glycemic markers in a Chinese population. J Clin Lab Anal 2017;31:e22097.

22 Watanabe M, Kokubo Y, Higashiyama A, et al. Serum 1,5-anhydroD-glucitol levels predict first-ever cardiovascular disease: an 11-year population-based cohort study in Japan, the Suita study. Atherosclerosis 2011;216:477-83.

23 Parrinello CM, Lutsey PL, Couper D, et al. Total short-term variability in biomarkers of hyperglycemia in older adults. Clin Chem 2015;61:1540-1.

24 Vital statistics in Japan (Ministry of health, labor and welfare), 2016. Available: http://www.mhlw.go.jp/english/database/db-hw/vsol.html [Accessed 12 Jan]. 